\title{
RGS Family Protein
}

National Cancer Institute

\section{Source}

National Cancer Institute. RGS Family Protein. NCI Thesaurus. Code C18166.

RGS family proteins activate GT Pase and regulate G protein signaling by stimulating the inactivation of heterotrimeric G proteins. RGS family proteins are responsible for the rapid turnoff of $\mathrm{G}$ protein-coupled receptor signaling pathways. There are indications that a subset of RGS proteins regulate specific G protein-coupled receptor pathways. 